\title{
Prognostic Significance of 14-3-3e, Aldo-keto Reductase Family 1 B10 and Metallothionein-1 in Hepatocellular Carcinoma
}

\author{
CHIH-YING WU ${ }^{1 *}$, YEE-JEE JAN ${ }^{1 *}$, BOR-SHENG KO ${ }^{2 *}$, YA-JU WU ${ }^{1,3}$, YI-JU WU ${ }^{4}$ and JUN-YANG LIOU ${ }^{4,5}$ \\ ${ }^{1}$ Department of Pathology and Laboratory Medicine, \\ Taichung Veterans General Hospital, Taichung, Taiwan, R.O.C.; \\ ${ }^{2}$ Department of Internal Medicine, National Taiwan University Hospital, Taipei, Taiwan, R.O.C.; \\ ${ }^{3}$ Department of Pathology, Taichung Veterans General Hospital, Chiayi Branch, Chiayi, Taiwan, R.O.C.; \\ ${ }^{4}$ Institute of Cellular and System Medicine, National Health Research Institutes, Zhunan, Taiwan, R.O.C.; \\ ${ }^{5}$ Graduate Institute of Basic Medical Science, China Medical University, Taichung, Taiwan, R.O.C.
}

\begin{abstract}
Background/Aim: Expression of $14-3-3 \varepsilon$ is associated with prognostic outcomes of hepatocellular carcinoma (HCC) patients. Metallothionein-1 (MT-1) proteins and aldo-keto-reductase family 1 B10 (AKR1B10) are considered potential tumor regulators of HCC. The aim of this study, was to examine the prognostic value of 14-3-3E, MT-1 and AKRIBIO expression in HCC. Materials and Methods: The expression levels of 14-3-3e, MT-1 and AKRIB10 in HCC cell lines and paraffin-embedded tissues were examined by western blotting and immunohistochemical analysis. Results: 14-3-3E positivity was significantly associated with decreased MT-1 expression in HCC. Patients with decreased MT-1 expression had worse survival rates and a higher risk of metastasis than 14-3-3E-positive HCC patients with unchanged MT-1 expression. Distinct expression patterns of 14-3-3E/MT-1/AKR1B10 were significantly associated with the metastatic incidence and survival rates of HCC patients. Patients with negative 14-3-3E staining in primary tumors had better prognostic outcomes. In contrast, patients with positive 14-3-3e staining, decreased MT-1 expression and no increase in AKRIB10 expression in primary tumors had the worst overall and disease-free survival rates and the highest metastatic risk. Conclusion: 14-3-3E, AKR1B10, and MT-1 act as potential prognostic biomarkers of $H C C$.
\end{abstract}

\footnotetext{
*These Authors contributed equally to this study.
}

Correspondence to: Dr. Jun-Yang Liou, Institute of Cellular and System Medicine, National Health Research Institutes, 35 Keyan Road, Zhunan, Miaoli County 35053, Taiwan, R.O.C. Tel: +886 37246166 ext. 38309 , Fax: +886 37587408, e-mail: jliou@nhri.org.tw

Key Words: 14-3-3e, AKR1B10, hepatocellular carcinoma, metastasis, MT-1.
Hepatocellular carcinoma (HCC) is a lethal malignancy that is associated with a high incidence of hepatitis in South Asia and Africa (1). Although recent progression of aggressive treatments have improved the clinical outcomes, however, the prognosis of HCC patients is dismal because of the frequent recurrence or distant metastasis (2-4). 14-3-3 proteins are implicated in the regulation of tumor progression of HCC (516). Selective isoforms of 14-3-3 proteins including 14-3-3 $\beta$, 14-3-3 $\gamma, 14-3-3 \varepsilon, 14-3-3 \sigma$, and 14-3-3 $\zeta$ are overexpressed in HCC $(6-11,14)$. An earlier study indicated that $14-3-3 \varepsilon$ is overexpressed and significantly associated with worse survival rate and higher incidence of distant metastasis of

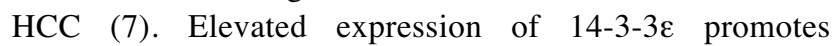
epithelial-mesenchymal transition (EMT) and cell migration via regulation of the expression of Zeb-1/E-cadherin and the $\mathrm{NFkB} /$ focal adhesion kinase (FAK) axis in HCC (12). Overexpression of $14-3-3 \varepsilon$ contributes to the regulation of cell proliferation and tumor growth in HCC (15). Targeting $14-3-3 \varepsilon$ and its downstream effectors is, therefore, a potential therapeutic and prognostic option for HCC.

Aldo-keto-reductase family 1 B10 (AKR1B10), a member of aldo-keto reductase family, plays a role in the development of cancers through detoxification of cytotoxic carbonyls. The expression of AKR1B10 is increased in a distinct type of malignancies, including lung carcinoma, uterine carcinoma, cholangiocarcinomas, breast cancer, and HCC (17-21). Silencing of AKR1B10 with siRNA has been demonstrated to suppress $\mathrm{HCC}$ tumor growth in mice during in vivo experiments (15). Although the expression of AKR1B10 is increased in primary HCC tumors, several studies have indicated that overexpression of AKR1B 10 is significantly associated with less aggressive and welldifferentiated HCC tumor, while a decrease in the expression of AKR1B10 is associated with advanced and malignant HCC $(15,22)$. These results suggest that AKR1B10 plays a paradoxical role in regulating tumor progression of HCC. 
Metallothionein-1 (MT-1) proteins are a group of proteins with a high affinity for binding with heavy metals (23-25). The expression of MT-1 proteins can be induced by oxidative stress and heavy metals (26-29). Induction of MT-1 expression scavenges heavy metals and free radicals to prevent cell or tissue from injury. Earlier studies have demonstrated that MT-1 isoforms are abundantly expressed in normal hepatic cells but their expression is significantly reduced in HCC (30-35). MT-1G, MT-1H, and MT-1M are reported to function as tumor suppressors in $\mathrm{HCC}$, whereas overexpression of MT-1 isoforms reduced HCC cell proliferation and tumor growth $(31,36,37)$. Moreover, results from several recent clinical studies have suggested that MT-1M and MT-1G promoter methylation may serve as a biomarker for $\operatorname{HCC}(36,38,39)$. MT- 1 proteins are, thus, considered as anti-tumor factors for $\operatorname{HCC}(27,30-32,36,39)$. Here, we aimed to elucidate the prognostic significance of 14-3-3e, AKR1B10 and MT-1 in HCC.

\section{Materials and Methods}

Cell culture and western blotting analysis. HCC cancer cell lines Huh-7, HepG2, and Hep3B were maintained as described previously (4, 8-11). The expression levels of 14-3-3e, MT-1, and AKR1B10 were determined by western blotting analysis. In brief, cells were harvested and lysed in ice-cold RIPA buffer (Millipore, Billerica, MA, USA) containing cocktail protease inhibitors (Roche Diagnostics, Mannheim, Germany). Cell lysates were centrifuged and protein concentration was determined using a Bio-Rad protein assay kit (BioRad Laboratories Inc., Hercules, CA, USA). Twenty micrograms of protein from each sample were applied to a gradient SDS-PAGE gel, followed by immunoblotting onto nitrocellulose (NC) membranes (GE Healthcare, Munich, Germany). Following blocking, the membranes were incubated with primary antibodies against $14-3-3 \varepsilon$ (sc-1020, Santa Cruz Biotechnology, Inc., Dallas, TX, USA), MT-1 (180133, Invitrogen, Carlsbad, CA, USA), AKR1B10 (sc-100501, Santa Cruz Biotechnology, Inc.), and actin (A5441, Sigma-Aldrich, St. Louis, USA). Then, the membranes were washed with PBST followed by incubation with horseradish peroxidase-conjugated secondary antibodies. The protein levels of $14-3-3 \varepsilon$, MT-1, AKR1B10, and actin control were determined using enhanced chemiluminescence reagents (PerkinElmer, Shelton, CT, USA).

Patients and clinical specimens. One hundred and nine HCC patients who underwent surgery for tumor resection at Taichung Veterans General Hospital were retrospectively enrolled (from January 1999 to December 2001) in this study. Tissues from 29 patients showed extrahepatic metastasis after surgery. Slides from paraffin-embedded surgical specimens of primary tumors with surrounding noncancerous liver tissues were subjected to immunohistochemical staining. The clinicopathological characteristics and clinical outcomes were collected for prognostic analysis. This study was approved by the Institutional Review Broad of Taichung Veterans General Hospital.

Immunohistochemical analysis. For immunohistochemistry analysis, an automatic immunostaining device and an ultraView detection kit were used to examine the expression levels of 14-3-3e, MT-1 and
AKR1B10 in paraffin-embedded tissues using primary antibodies against 14-3-3e (sc-1020, Santa Cruz Biotechnology, Inc.), MT-1 (180133, Invitrogen), and AKR1B10 (sc-100501, Santa Cruz Biotechnology, Inc.). Specimens not incubated with primary antibodies were used as negative controls. The intensity of 14-3-3e, MT-1, and AKR1B10 staining was semi-quantitatively scored by a Quick-score (Q-score) method based on the determination of the intensity and heterogeneity in each sample (7-9, 12-15). Regarding staining intensity, a negative intensity was scored as 0 ; a weak intensity as 1 ; a moderate intensity as 2 ; and a strong intensity as 3 . To determine heterogeneity, staining of tumor cells positively with $14-3-3 \varepsilon$, MT-1, and AKR1B10 was scored as; $0 \%$ of cells stained as $0 ; 1 \%-25 \%$ as 1 ; $26 \%-50 \%$ as $2 ; 51 \%-75 \%$ as 3 ; and $76 \%-100 \%$ as 4 . The Q-score was the sum of intensity and heterogeneity scores (ranged from 0 to 7 ). Each sample was evaluated independently and blindly by 2 pathologists. For data analysis, a Q-score $\geq 2$ (tumors $v s$. non-cancerous tissues) was considered a positive expression, and a Q-score $<2$ was considered a negative expression of 14-3-3e. For AKR1B10 expression, a Q-score $\leq 2$ (tumors vs. non-cancerous tissues) was defined as an increase in AKR1B10 expression, whereas Q-score $<2$ was considered as no increase in AKR1B10 expression. For estimation of MT-1 expression, a Q-score $\geq 2$ (tumors $v s$. non-cancerous tissues) was defined as a decrease in MT-1. Some rare cases with $<5 \%$ weakly stained specimens were considered to have negative expression.

Statistical analysis. One-way ANOVA was used to analyze the clinicopathological variables of HCC patients. Multivariate logistic regression was used to analyze factors governing metastasis. Kaplan-Meier curves were plotted, and the log-rank test was performed to analyze time-related probabilities of extrahepatic metastasis, rates of overall survival, and disease-free survival. $p<0.05$ indicated statistical significance.

\section{Results}

Protein expression of 14-3-3e, MT-1, and AKR1B10 in HCC cell lines. Our previous reports have indicated that the expression of several regulators including AKR1B10 is modulated by $14-3-3 \varepsilon$ in HCC (15). Increasing number of studies have demonstrated that MT-1 acts as a tumor suppressor in regulating tumorigenesis of HCC. Here, we aimed to investigate whether 14-3-3e interacts with MT-1 and whether AKR1B10 could be considered a potential prognostic marker of HCC. In this study, the expression levels of 14-3$3 \varepsilon$, MT-1, and AKR1B10 in Huh-7, HepG2, and Hep3B HCC cells were firstly examined. Although the expression of 14-3$3 \varepsilon$ could be detected in all these cell lines, the levels of 14-3$3 \varepsilon$ in Hep3B were relatively higher than in Huh-7 and HepG2 cells (Figure 1, upper panel). Furthermore, MT-1 was abundantly expressed in HepG2 but weakly expressed in Huh7 cells. AKR1B10 was expressed in both Huh-7 and HepG2 cells. However, the expression levels of MT-1 and AKR1B10 were rarely detectable in Hep3B cells (Figure 1).

Correlation of 14-3-3e expression with MT-1. The expression of $14-3-3 \varepsilon$ and MT-1 was examined in paraffin-embedded primary HCC tumor specimens with surrounding non- 


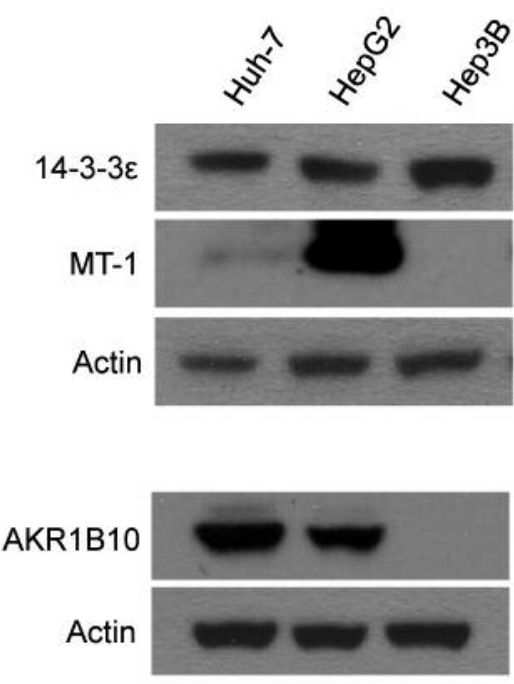

Figure 1. Protein expression of 14-3-3e, MT-1, and AKR1B10 in Huh-7, HepG2, and Hep3B HCC cells was determined by western blotting analysis.

Table I. Correlation of MT-1 expression with 14-3-3e in primary tumors of HCC patients.

\begin{tabular}{lccc}
\hline & \multicolumn{2}{c}{ MT-1 } & \\
\cline { 2 - 3 } & Decrease & No decrease & Total \\
\hline $14-3-3 \varepsilon$ & & & \\
Negative & 16 & 27 & 43 \\
Positive & 41 & 25 & 66 \\
Total & 57 & 52 & 109 \\
\hline
\end{tabular}

$p=0.011$.

cancerous parenchyma in a cohort study of 109 patients by immunohistochemical staining. Negative control slides were not stained with 14-3-3e and MT-1 antibodies (Figure 2A and $2 B$ ). $14-3-3 \varepsilon$ was positively stained in 66 out of 109 primary $\mathrm{HCC}$ tumors but negatively stained in non-cancerous tissues adjacent to tumor specimens (Figure 2C and Table I). MT-1 was positively stained in normal liver tissues, but decreased expression of MT-1 was found in 57 out of 109 primary HCC tumors (Figure 2D and Table I). Thus, the expression of $14-3-3 \varepsilon$ was inversely correlated with MT-1 expression $(p=0.011)$ (Table I).

Altered expression of MT-1 and positive staining of 14-3-3E in primary HCC tissues and association with patient survival as well as extrahepatic metastasis. In this study, the correlation of MT-1 expression with 14-3-3e expression and the clinicopathological characteristics of HCC patients was investigated. Decrease in MT-1 expression was significantly
Table II. Correlation of MT-1 expression with $14-3-3 \varepsilon$ and clinicopathological characteristics in primary tumors of HCC patients.

\begin{tabular}{|c|c|c|}
\hline Parameters & $\begin{array}{c}\text { Decrease of MT-1 } \\
(\mathrm{Q}-\text { score decrease } \geq 2) \\
\%(\mathrm{n})\end{array}$ & $p$-Value \\
\hline Overall $(n=109)$ & $52.3 \%(57)$ & \\
\hline Age & & NS \\
\hline$\geq 60$ years $(n=54)$ & $44.4 \%(24)$ & \\
\hline$<60$ years $(\mathrm{n}=55)$ & $60.0 \%(33)$ & \\
\hline Gender & & NS \\
\hline Male $(\mathrm{n}=82)$ & $53.7 \%(44)$ & \\
\hline Female $(n=27)$ & $48.1 \%(13)$ & \\
\hline Histology grade & & NS \\
\hline $1(n=7)$ & $57.1 \%(4)$ & \\
\hline $2(n=78)$ & $46.2 \%(36)$ & \\
\hline $3(n=24)$ & $70.8 \%(17)$ & \\
\hline Types of surgery & & NS \\
\hline Wedge resection $(n=39)$ & $51.3 \%(20)$ & \\
\hline Segmentectomy $(n=53)$ & $50.9 \%(27)$ & \\
\hline Lobectomy $(\mathrm{n}=17)$ & $58.8 \%(10)$ & \\
\hline Surgical margin & & NS \\
\hline Free $(n=83)$ & $48.2 \%(40)$ & \\
\hline Involved $(n=26)$ & $65.4 \%(17)$ & \\
\hline BCLC staging & & NS \\
\hline Not available $(n=3)$ & & \\
\hline Early (stage A1 to A4) $(n=56)$ & $44.6 \%(25)$ & \\
\hline Intermediate (stage B) $(n=48)$ & $60.4 \%(29)$ & \\
\hline Advanced (stage C) $(\mathrm{n}=2)$ & $100.0 \%(2)$ & \\
\hline Tumor size & & $<0.001^{\#}$ \\
\hline$\geq 5.0 \mathrm{~cm}(\mathrm{n}=34)$ & $76.5 \%(26)$ & \\
\hline$<5.0 \mathrm{~cm}(\mathrm{n}=75)$ & $41.3 \%(31)$ & \\
\hline Tumor multiplicity & & NS \\
\hline Single $(n=84)$ & $56.0 \%(47)$ & \\
\hline Multiple $(n=25)$ & $40.0 \%(10)$ & \\
\hline Capsular formation & & \\
\hline Not available $(n=8)$ & & $0.024^{\#}$ \\
\hline Yes $(n=58)$ & $44.8 \%(26)$ & \\
\hline No $(n=43)$ & $67.4 \%(29)$ & \\
\hline Micro-vascular thrombi & & $0.036^{\#}$ \\
\hline Yes $(n=47)$ & $63.8 \%(30)$ & \\
\hline No $(n=62)$ & $43.5 \%(27)$ & \\
\hline Liver cirrhosis & & $0.003^{\#}$ \\
\hline Not available $(n=3)$ & & \\
\hline Yes $(n=56)$ & $39.3 \%(22)$ & \\
\hline No $(n=50)$ & $68.0 \%(34)$ & \\
\hline Viral hepatitis & & $0.014^{\#}$ \\
\hline Not available $(\mathrm{n}=7)$ & & \\
\hline Hepatitis B $(n=54)$ & $66.7 \%(36)$ & \\
\hline Hepatitis C $(n=30)$ & $40.0 \%(12)$ & \\
\hline Both $(n=15)$ & $26.7 \%(4)$ & \\
\hline None $(n=3)$ & $33.3 \%(1)$ & \\
\hline Alpha-fetoprotein level & & NS \\
\hline Not available $(\mathrm{n}=12)$ & & \\
\hline$\geq 80 \mathrm{ng} / \mathrm{ml}(\mathrm{n}=35)$ & $48.6 \%(17)$ & \\
\hline$<80 \mathrm{ng} / \mathrm{ml}(\mathrm{n}=62)$ & $51.6 \%(32)$ & \\
\hline Subsequent extrahepatic metastasis & & NS \\
\hline Yes $(n=29)$ & $58.6 \%(17)$ & \\
\hline No $(n=80)$ & $50.0 \%(40)$ & \\
\hline $14-3-3 \varepsilon$ positivity & & $0.011^{\#}$ \\
\hline Yes $(\mathrm{n}=66)$ & $62.1 \%(41)$ & \\
\hline No $(n=43)$ & $37.2 \%(16)$ & \\
\hline
\end{tabular}

BCLC: Barcelona-Clinic Liver Cancer; NS: not significant; Q-score: Quick-score; ${ }^{*} p<0.05$. 

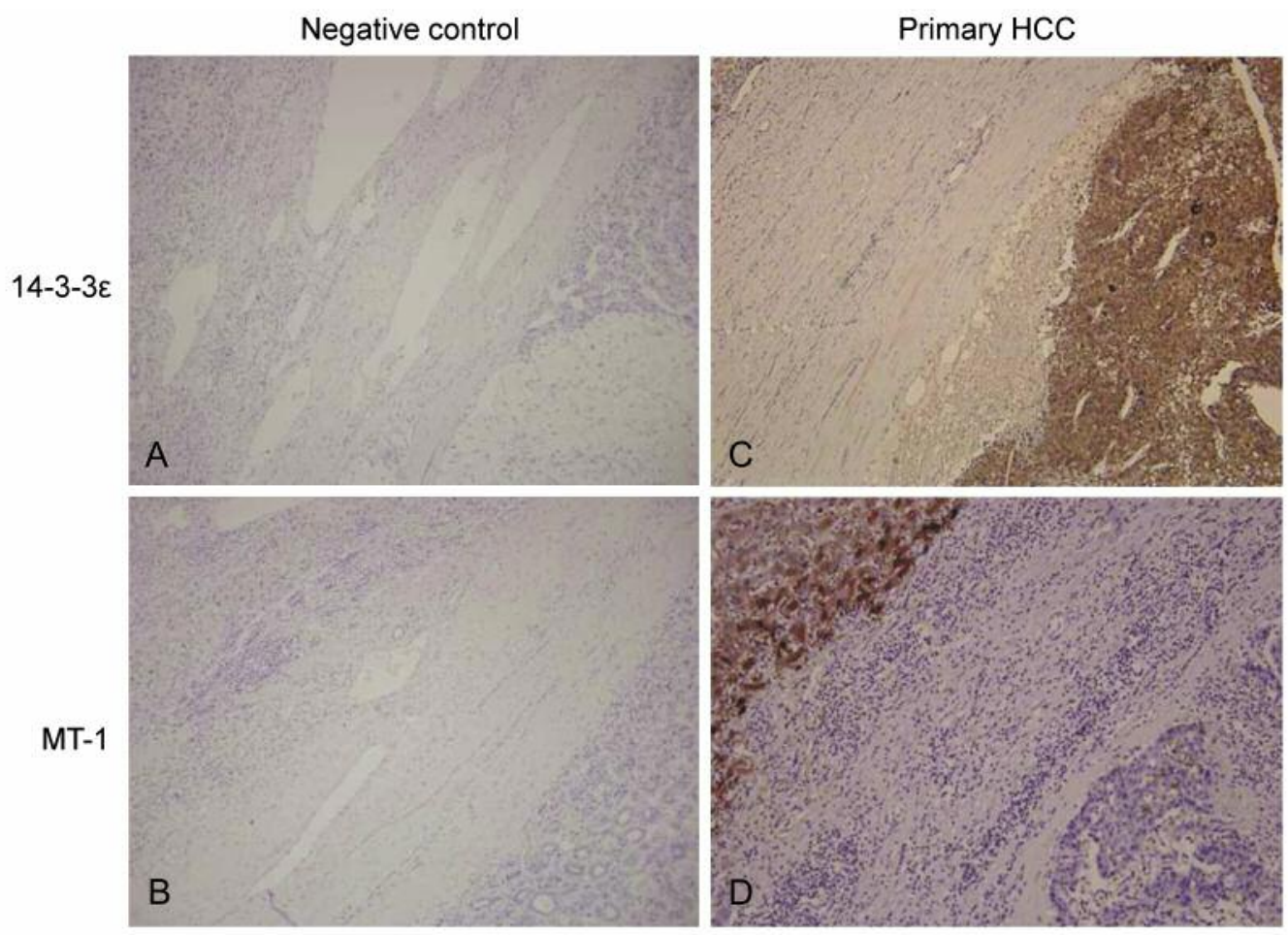

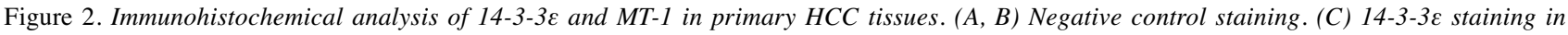
representative primary $H C C$. (D) MT-1 staining in representative primary HCC.

associated with parameters of tumor size $(p<0.001)$, capsular formation $(p=0.024)$, micro-vascular thrombi $(p=0.036)$, liver cirrhosis $(p=0.003)$, viral hepatitis $(p=0.014)$, and 14 3-3e-positive staining $(p=0.011)$ (Table II).

We have previously reported that overexpression of 14-3$3 \varepsilon$ is associated with a higher risk of tumor metastasis and poor survival of HCC patients $(7,12)$. In this study, patients with decreased MT-1 expression exhibited worse rates of overall survival (Figure 3A, left panel) and disease-free survival (Figure 3B, left panel) as well as a higher risk of extrahepatic metastasis (Figure 3C, left panel) than those with unchanged expression of MT-1 among 14-3-3e-positive HCC patients. In contrast, there was no significant difference in overall survival rate, disease-free survival rate, and higher metastatic risk in 14-3-3e-negative patients with HCC exhibiting decrease or no decrease in MT-1 expression (Figure 3A, B and C, right panels).

Prognostic value of 14-3-3E combined with AKRIB10 and MT1 in HCC patients. We have previously reported that increased expression of AKR1B10 is associated with surgical margin, BCLC staging, subsequent extrahepatic metastasis, and 14-3$3 \varepsilon$ positivity (15). However, no increase in AKR1B10 expression was associated with subsequent extrahepatic metastasis (15). In this study, the prognostic value of $14-3-3 \varepsilon$ combined with MT-1 and AKR1B10 was examined. A total of 109 HCC patients were divided into 4 groups: Group 1: 14-3$3 \varepsilon(+) / \mathrm{MT}-1(-) / \mathrm{AKR} 1 \mathrm{~B} 10(-)$; Group 2: 14-3-3e(+)/MT$1(-) / \mathrm{AKR} 1 \mathrm{~B} 10(+)$ or $14-3-3 \varepsilon(+) / \mathrm{MT}-1(+) / \mathrm{AKR} 1 \mathrm{~B} 10(-)$; Group 3: 14-3-3e(+)/MT-1(+)/AKR1B10(+); and Group 4: 143-3e(-)/MT-1 any/AKR1B10 any. HCC patients exhibiting 143-3e-negative staining in primary tumors (Group 4) had better prognostic outcomes of overall survival, disease-free survival, and extrahepatic metastasis (Figure 4A-C) than those in other groups. In contrast, patients with 14-3-3e-positive staining combined with a decrease in MT-1 expression and no increase in AKR1B10 expression in the primary tumors (Group 1) had the worst overall survival $(p<0.001)$ and disease-free survival rates $(p=0.008)$ (Figure 4A and B), as well as the highest metastatic risk ( $p=0.007)$ (Figure $4 C$ ), compared to those of patients in other groups.

\section{Discussion}

Overexpression of $14-3-3 \varepsilon$ is implicated in the regulation of HCC tumor progression, including promotion of cell proliferation, epithelial-mesenchymal transition, cell migration, invasion, tumor growth, and metastasis $(7,12,13$, 
A

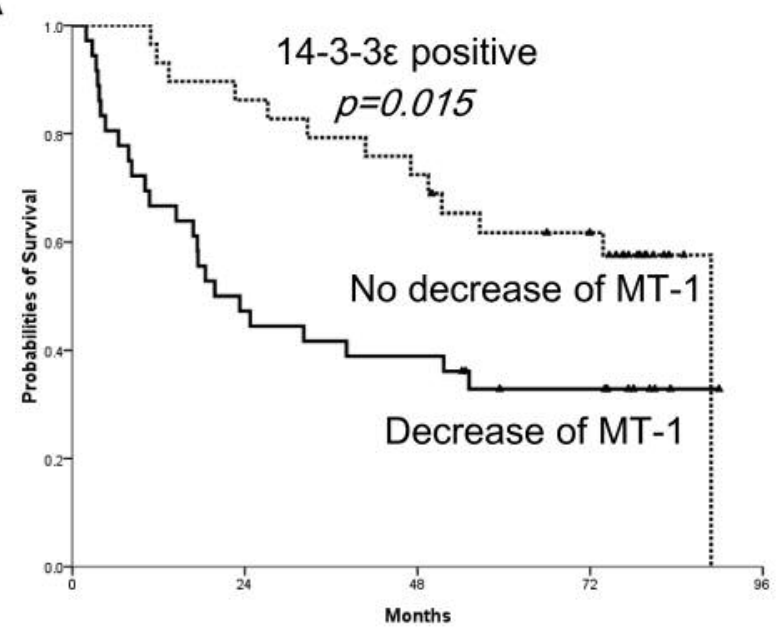

B

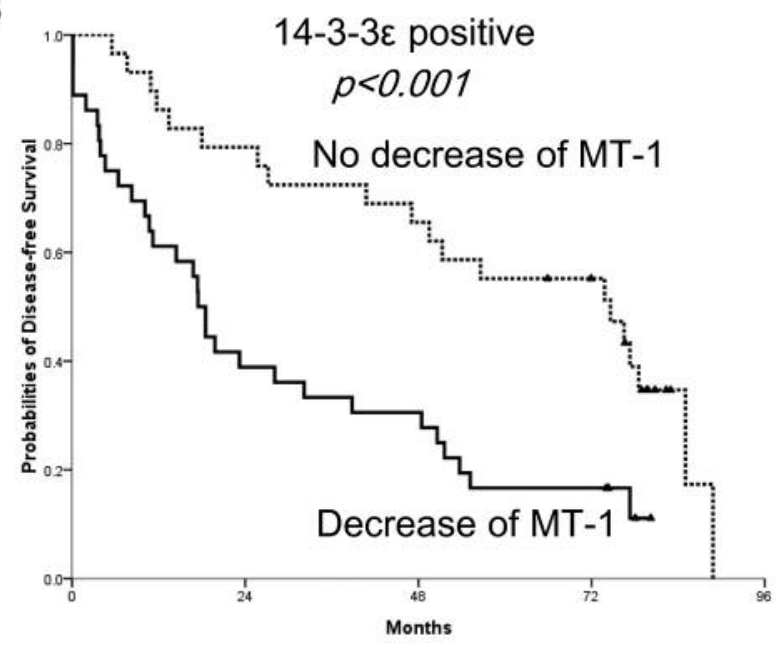

C

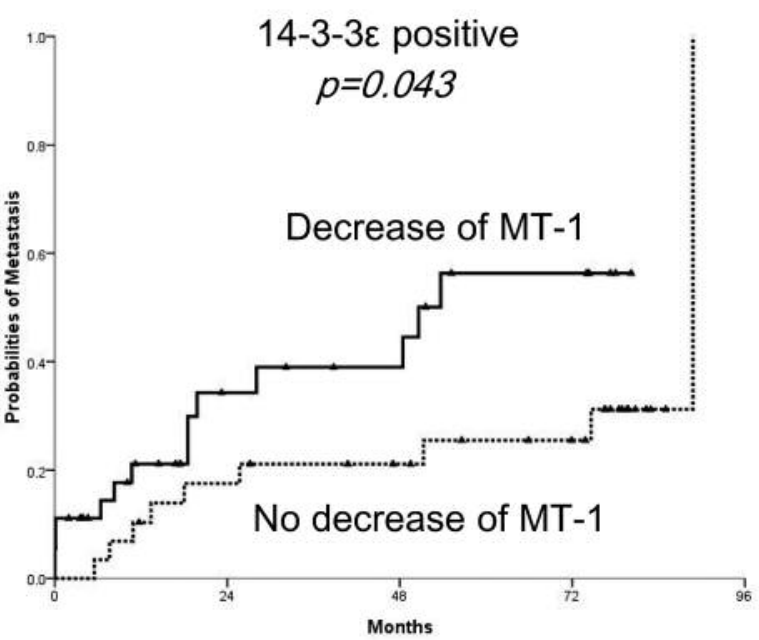

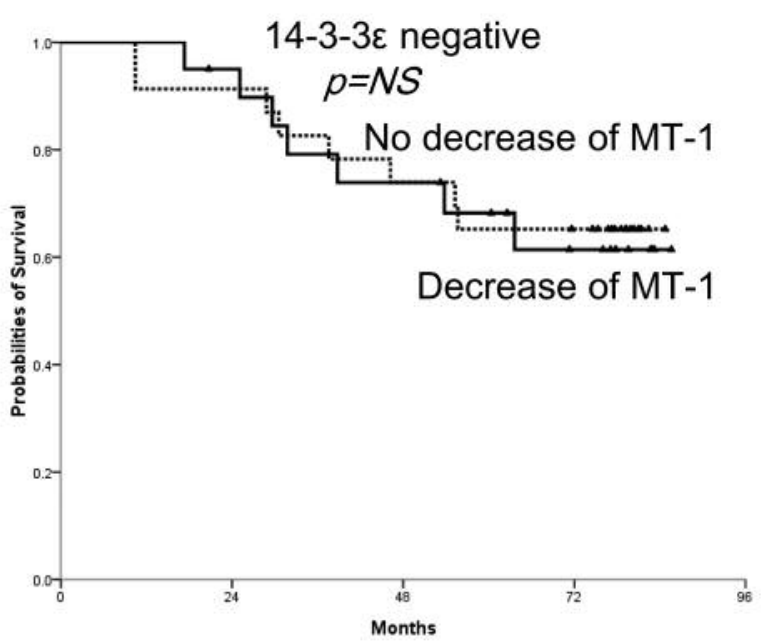
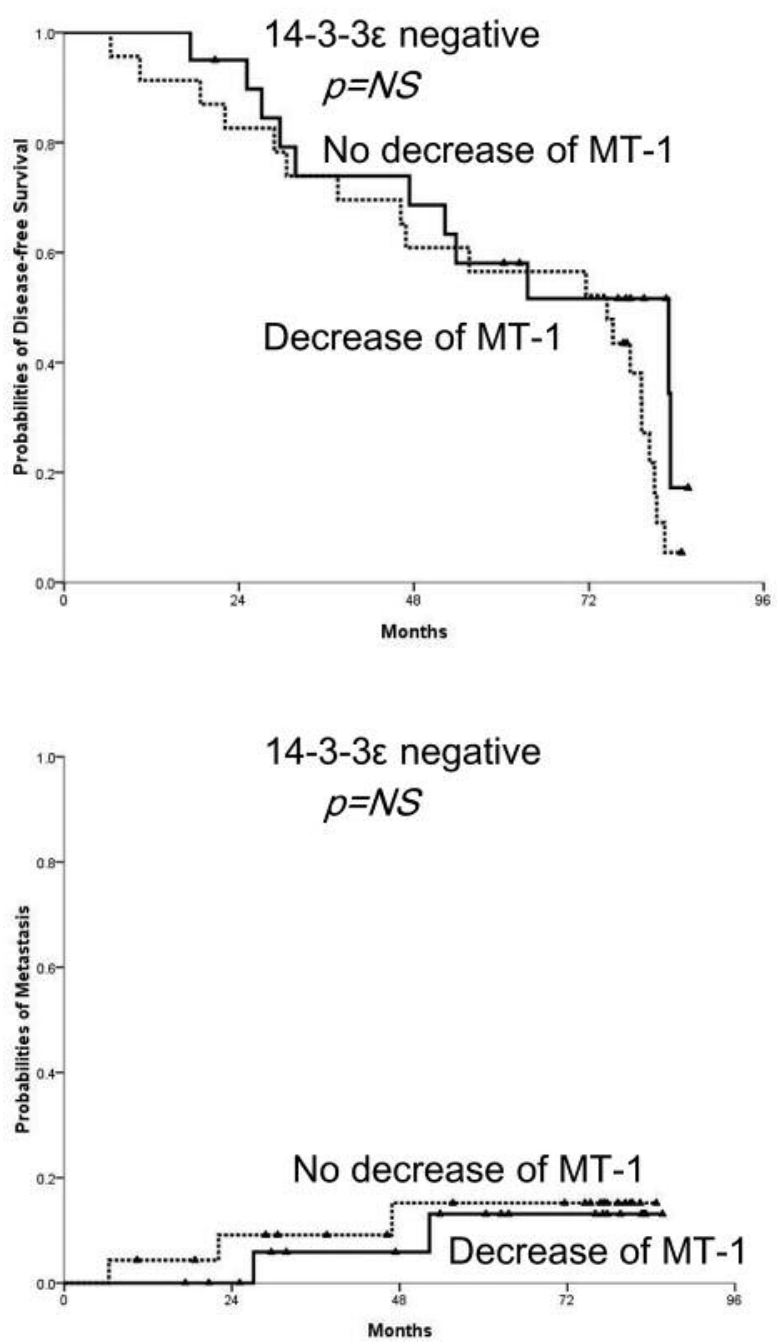

Figure 3. Kaplan-Meier analysis of 14-3-3e positivity and decrease of MT-1 expression with prognostic outcomes in primary HCC tumors. (A) Overall survival. (B) Disease-free survival. (C) Metastasis. 
A

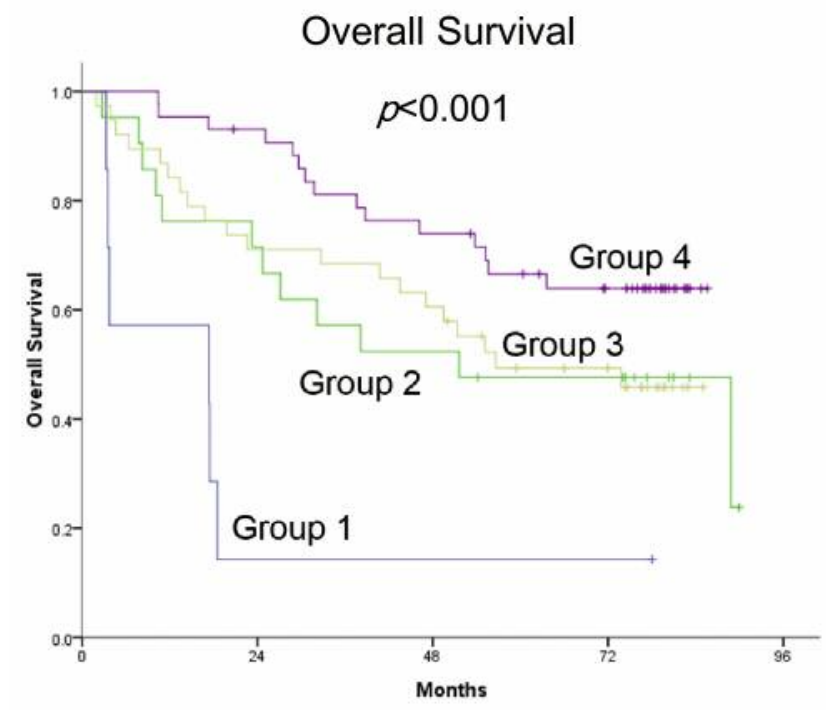

C

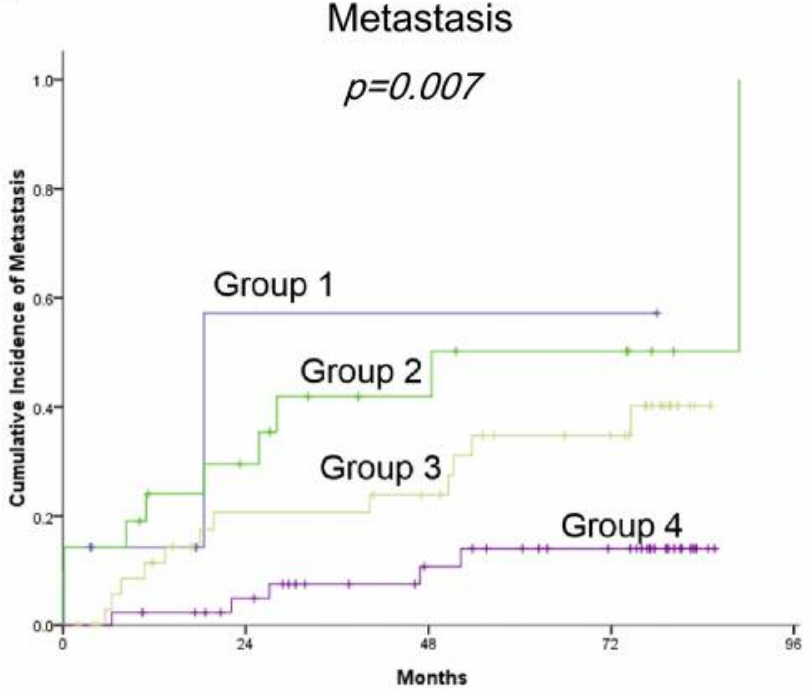

B

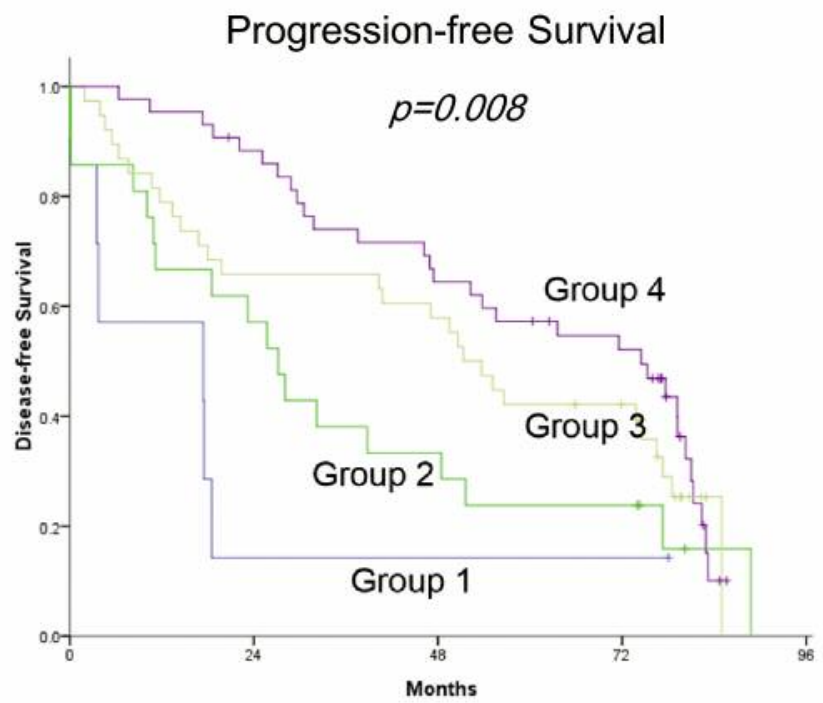

Figure 4. Kaplan-Meier analysis of 14-3-3E positivity, decrease of MT-1 expression and no increase of AKR1B10 expression with prognostic outcomes in primary HCC tumors. (A) Overall survival. (B) Disease-free survival. (C) Metastasis.

15). AKR1B10 is expressed in early HCC and silencing of AKR1B10 by siRNA significantly attenuates cell proliferation and tumor growth. Intriguingly, HCC patients with an increase in AKR1B10 expression have better clinical outcomes than those without increase in AKR1B10 expression. The decrease in AKR1B10 expression is associated with more advanced and malignant $\operatorname{HCC}(15,19$, 22, 40). Moreover, MT-1 proteins are abundantly expressed in normal liver and downregulation of MT-1 is associated with poor prognosis in $\mathrm{HCC}(15,19,22)$. In this study, HCC patients positive for $14-3-3 \varepsilon$, with decreased MT-1 expression and no increase in AKR1B10 expression were found to have the worst prognostic outcomes. Our results revealed that $14-3-3 \varepsilon$, AKR1B10, and MT-1 are potential prognostic markers for survival and metastasis of HCC. Although our previous study indicated that AKR1B10 expression is not associated with viral hepatitis in HCC patients (15), results from a recent study revealed that 
hepatitis B virus (HBV)-positive patients with high hepatic AKR1B10 expression had an increased risk of HCC development (41). In contrast, it has been reported that high expression of AKR1B10 is associated with a low risk of early tumor recurrence in patients with HBV-related HCC (40). These results suggested that highly expressed AKR1B10 might contribute to the development of early HCC but is associated with attenuated HCC malignancy. Previous studies have shown that overexpression of MT-1 suppressed cancer cell proliferation and tumor growth in $\operatorname{HCC}(31,37)$. In the present study, the expression levels of AKR1B 10 and MT-1 were rarely detectable in Hep3B cells (Figure 1). As Hep3B is a poorly differentiated HCC cell line with deleted p53 and HBV positivity, these results provided evidence to support the potential prognostic role of decreased expression of AKR1B10 and MT-1 in more advanced or metastatic HCC.

MT-1 proteins are comprised of at least 13 isoforms (42) and several isoforms including MT-1M, MT-1G, and MT-1H are reported to function as tumor suppressors in $\operatorname{HCC}(31,36$, 37, 39). Our previous study indicated that AKR1B10 is regulated by $14-3-3 \varepsilon$ through a $\beta$-catenin-dependent mechanism. However, regulation of MT-1 expression by 14$3-3 \varepsilon$ has never been reported. Further investigation is needed to elucidate the interaction and association of MT-1 with 14$3-3 \varepsilon$ in HCC. Moreover, the antibody currently available for determining MT-1 levels using western blot or IHC analysis is not specific and may recognize most of the MT-1 isoforms. Thus, whether the combination of 14-3-3 $\varepsilon$ and AKR1B10 with particular isoforms of MT- 1 act as potential prognostic markers for $\mathrm{HCC}$ remains a topic for further investigation.

We have previously reported that AKR1B10 is overexpressed in HCC and increase in AKR1B10 expression induces cell proliferation and tumor growth (15). In contrast, we have found that silencing of AKR1B10 induces snail and vimentin expression, and decrease in AKR1B10 expression is significantly associated with worse overall survival rate and higher risk of metastasis of HCC (15). Moreover, the expression of AKR1B10 is almost undetectable in HCC cells with highly invasive capacity (15). These results suggest that AKR1B10 might play a paradoxical role in regulating tumor progression of HCC.

14-3-3 proteins can be detected in the extracellular fractions and secreted exosomes $(16,43)$. Furthermore, it has been reported that AKR1B10 and MT-1 are secreted factors (44-46). We have shown that 14-3-3e, MT-1, and AKR1B10 act as potential prognostic biomarkers of HCC. However, additional studies are required to investigate whether the combination of 14-3-3e, MT-1, and AKR1B10 acts also as a potential prognostic serum marker for HCC.

In this study, patients of 14-3-3e-positive staining combined with decrease of MT-1 and no increase of AKR1B10 in primary tumors of HCC were found to have the worst overall and disease-free survival rates as well as the highest metastatic risk. Our results indicate for the first time that the combination of $14-3-3 \varepsilon$, AKR1B10 and MT-1 is a potential prognostic biomarker of HCC.

\section{Conflicts of Interest}

The Authors declare no conflict of interest in regard to this study.

\section{Acknowledgements}

The Authors thank the Comprehensive Cancer Center of Taichung Veterans General Hospital for providing information concerning the outcomes of patients. This work was supported by the National Health Research Institutes (06A1-CSPP07-014) and the Ministry of Science and Technology (105-2320-B-400-021 and 106-2320-B400-023) of Taiwan.

\section{References}

1 El-Serag HB and Rudolph KL: Hepatocellular carcinoma: Epidemiology and molecular carcinogenesis. Gastroenterology 132(7): 2557-2576, 2007.

2 El-Serag HB, Marrero JA, Rudolph L and Reddy KR: Diagnosis and treatment of hepatocellular carcinoma. Gastroenterology 134(6): 1752-1763, 2008.

3 Bruix J, Sherman M, Llovet JM, Beaugrand M, Lencioni R, Burroughs AK, Christensen E, Pagliaro L, Colombo M and Rodes J: Clinical management of hepatocellular carcinoma. Conclusions of the barcelona-2000 easl conference. European association for the study of the liver. J Hepatol 35(3): 421-430, 2001.

4 Natsuizaka M, Omura T, Akaike T, Kuwata Y, Yamazaki K, Sato T, Karino Y, Toyota J, Suga T and Asaka M: Clinical features of hepatocellular carcinoma with extrahepatic metastases. J Gastroenterol Hepatol 20(11): 1781-1787, 2005.

5 Tzivion G, Gupta VS, Kaplun L and Balan V: 14-3-3 proteins as potential oncogenes. Semin Cancer Biol 16(3): 203-213, 2006.

6 Wu YJ, Jan YJ, Ko BS, Liang SM and Liou JY: Involvement of 14-3-3 proteins in regulating tumor progression of hepatocellular carcinoma. Cancers (Basel) 7(2): 1022-1036, 2015.

7 Ko BS, Chang TC, Hsu C, Chen YC, Shen TL, Chen SC, Wang J, Wu KK, Jan YJ and Liou JY: Overexpression of 14-3-3epsilon predicts tumour metastasis and poor survival in hepatocellular carcinoma. Histopathology 58(5): 705-711, 2011.

8 Liu TA, Jan YJ, Ko BS, Chen SC, Liang SM, Hung YL, Hsu C, Shen TL, Lee YM, Chen PF, Wang J, Shyue SK and Liou JY: Increased expression of 14-3-3beta promotes tumor progression and predicts extrahepatic metastasis and worse survival in hepatocellular carcinoma. Am J Pathol 179(6): 2698-2708, 2011.

9 Ko BS, Lai IR, Chang TC, Liu TA, Chen SC, Wang J, Jan YJ and Liou JY: Involvement of 14-3-3gamma overexpression in extrahepatic metastasis of hepatocellular carcinoma. Hum Pathol 42(1): 129-135, 2011.

10 Huang XY, Ke AW, Shi GM, Zhang X, Zhang C, Shi YH, Wang XY, Ding ZB, Xiao YS, Yan J, Qiu SJ, Fan J and Zhou J: Alphab-crystallin complexes with 14-3-3zeta to induce epithelial-mesenchymal transition and resistance to sorafenib in hepatocellular carcinoma. Hepatology 57(6): 2235-2247, 2013. 
11 Choi JE, Hur W, Jung CK, Piao LS, Lyoo K, Hong SW, Kim SW, Yoon HY and Yoon SK: Silencing of 14-3-3zeta overexpression in hepatocellular carcinoma inhibits tumor growth and enhances chemosensitivity to cis-diammined dichloridoplatium. Cancer Lett 303(2): 99-107, 2011.

12 Liu TA, Jan YJ, Ko BS, Liang SM, Chen SC, Wang J, Hsu C, Wu YM and Liou JY: 14-3-3epsilon overexpression contributes to epithelial-mesenchymal transition of hepatocellular carcinoma. PLoS One 8(3): e57968, 2013.

13 Ko BS, Jan YJ, Chang TC, Liang SM, Chen SC, Liu TA, Wu YM, Wang J and Liou JY: Upregulation of focal adhesion kinase by 14-3-3epsilon via nfkappab activation in hepatocellular carcinoma. Anticancer Agents Med Chem 13(4): 555-562, 2013.

14 Liu CC, Jan YJ, Ko BS, Wu YM, Liang SM, Chen SC, Lee YM, Liu TA, Chang TC, Wang J, Shyue SK, Sung LY and Liou JY: 14-3-3sigma induces heat shock protein 70 expression in hepatocellular carcinoma. BMC Cancer 14: 425, 2014.

15 Liu TA, Jan YJ, Ko BS, Wu YJ, Lu YJ, Liang SM, Liu CC, Chen SC, Wang J, Shyue SK and Liou JY: Regulation of aldo-ketoreductase family 1 b10 by 14-3-3epsilon and their prognostic impact of hepatocellular carcinoma. Oncotarget 6(36): 38967-38982, 2015.

16 Liu CC, Chang TC, Lin YT, Yu YL, Ko BS, Sung LY and Liou JY: Paracrine regulation of matrix metalloproteinases contributes to cancer cell invasion by hepatocellular carcinoma-secreted 143-3sigma. Oncotarget 7(24): 36988-36999, 2016.

17 Fukumoto S, Yamauchi N, Moriguchi H, Hippo Y, Watanabe A, Shibahara J, Taniguchi H, Ishikawa S, Ito H, Yamamoto S, Iwanari H, Hironaka M, Ishikawa Y, Niki T, Sohara Y, Kodama T, Nishimura M, Fukayama M, Dosaka-Akita H and Aburatani $\mathrm{H}$ : Overexpression of the aldo-keto reductase family protein akr1b10 is highly correlated with smokers' non-small cell lung carcinomas. Clin Cancer Res 11(5): 1776-1785, 2005.

18 Yoshitake H, Takahashi M, Ishikawa H, Nojima M, Iwanari H, Watanabe A, Aburatani H, Yoshida K, Ishi K, Takamori K, Ogawa H, Hamakubo T, Kodama T and Araki Y: Aldo-keto reductase family 1 , member b10 in uterine carcinomas: A potential risk factor of recurrence after surgical therapy in cervical cancer. Int J Gynecol Cancer 17(6): 1300-1306, 2007.

19 Heringlake S, Hofdmann M, Fiebeler A, Manns MP, Schmiegel $\mathrm{W}$ and Tannapfel A: Identification and expression analysis of the aldo-ketoreductase1-b10 gene in primary malignant liver tumours. J Hepatol 52(2): 220-227, 2010.

20 Ma J, Luo DX, Huang C, Shen Y, Bu Y, Markwell S, Gao J, Liu J, Zu X, Cao Z, Gao Z, Lu F, Liao DF and Cao D: Akr1b10 overexpression in breast cancer: Association with tumor size, lymph node metastasis and patient survival and its potential as a novel serum marker. Int J Cancer 131(6): E862-871, 2012.

21 Chung YT, Matkowskyj KA, Li H, Bai H, Zhang W, Tsao MS, Liao J and Yang GY: Overexpression and oncogenic function of aldo-keto reductase family $1 \mathrm{~b} 10$ (akr1b10) in pancreatic carcinoma. Mod Pathol 25(5): 758-766, 2012.

22 Ha SY, Song DH, Lee JJ, Lee HW, Cho SY and Park CK: High expression of aldo-keto reductase $1 \mathrm{~b} 10$ is an independent predictor of favorable prognosis in patients with hepatocellular carcinoma. Gut Liver 8(6): 648-654, 2014.

23 Webb M: Toxicological significance of metallothionein. Experientia Suppl 52: 109-134, 1987.

24 Andrews GK: Regulation of metallothionein gene expression by oxidative stress and metal ions. Biochem Pharmacol 59(1): 95104, 2000 .
25 Ebara M, Fukuda H, Hatano R, Saisho H, Nagato Y, Suzuki K, Nakajima K, Yukawa M, Kondo F, Nakayama A and Sakurai H: Relationship between copper, zinc and metallothionein in hepatocellular carcinoma and its surrounding liver parenchyma. J Hepatol 33(3): 415-422, 2000.

26 Fukada T, Yamasaki S, Nishida K, Murakami M and Hirano T: Zinc homeostasis and signaling in health and diseases: Zinc signaling. J Biol Inorg Chem 16(7): 1123-1134, 2011.

27 Meplan C, Richard MJ and Hainaut P: Metalloregulation of the tumor suppressor protein p53: Zinc mediates the renaturation of p53 after exposure to metal chelators in vitro and in intact cells. Oncogene 19(46): 5227-5236, 2000.

28 Arnal N, de Alaniz MJ and Marra CA: Cytotoxic effects of copper overload on human-derived lung and liver cells in culture. Biochim Biophys Acta 1820(7): 931-939, 2012.

29 Liu J, Qu W and Kadiiska MB: Role of oxidative stress in cadmium toxicity and carcinogenesis. Toxicol Appl Pharmacol 238(3): 209-214, 2009.

30 Tao X, Zheng JM, Xu AM, Chen XF and Zhang SH: Downregulated expression of metallothionein and its clinicopathological significance in hepatocellular carcinoma. Hepatol Res 37(10): 820-827, 2007.

$31 \mathrm{Fu}$ CL, Pan B, Pan JH and Gan MF: Metallothionein 1m suppresses tumorigenesis in hepatocellular carcinoma. Oncotarget 8(20): 33037-33046, 2017.

32 Liu Z, Ye Q, Wu L, Gao F, Xie H, Zhou L, Zheng S and Xu X: Metallothionein 1 family profiling identifies $\mathrm{mt} 1 \mathrm{x}$ as a tumor suppressor involved in the progression and metastastatic capacity of hepatocellular carcinoma. Mol Carcinog 57: 1434-1444, 2018.

33 Park Y and Yu E: Expression of metallothionein-1 and metallothionein-2 as a prognostic marker in hepatocellular carcinoma. J Gastroenterol Hepatol 28(9): 1565-1572, 2013.

34 Tanimoto K, Akbar SM, Yamauchi Y, Michitaka K, Horiike N and Onji M: Immunohistochemical localization of metallothionein in hepatocellular carcinoma: Preferential expression in non-cancerous cirrhotic nodules. Oncol Rep 5(4): 805-809, 1998.

35 Huang GW and Yang LY: Metallothionein expression in hepatocellular carcinoma. World J Gastroenterol 8(4): 650-653, 2002.

36 Mao J, Yu H, Wang C, Sun L, Jiang W, Zhang P, Xiao Q, Han D, Saiyin H, Zhu J, Chen T, Roberts LR, Huang H and Yu L: Metallothionein $\mathrm{mt} 1 \mathrm{~m}$ is a tumor suppressor of human hepatocellular carcinomas. Carcinogenesis 33(12): 2568-2577, 2012.

37 Zheng Y, Jiang L, Hu Y, Xiao C, Xu N, Zhou J and Zhou X: Metallothionein $1 \mathrm{~h}(\mathrm{mt} 1 \mathrm{~h})$ functions as a tumor suppressor in hepatocellular carcinoma through regulating wnt/beta-catenin signaling pathway. BMC Cancer 17(1): 161, 2017.

38 Ji XF, Fan YC, Gao S, Yang Y, Zhang JJ and Wang K: Mt1m and $\mathrm{mt} 1 \mathrm{~g}$ promoter methylation as biomarkers for hepatocellular carcinoma. World J Gastroenterol 20(16): 4723-4729, 2014.

39 Kanda M, Nomoto S, Okamura Y, Nishikawa Y, Sugimoto H, Kanazumi N, Takeda $\mathrm{S}$ and Nakao A: Detection of metallothionein $1 \mathrm{~g}$ as a methylated tumor suppressor gene in human hepatocellular carcinoma using a novel method of double combination array analysis. Int J Oncol 35(3): 477-483, 2009.

40 Wang YY, Qi LN, Zhong JH, Qin HG, Ye JZ, Lu SD, Ma L, Xiang BD, Li LQ and You XM: High expression of akr1b10 predicts low risk of early tumor recurrence in patients with hepatitis b virus-related hepatocellular carcinoma. Sci Rep 7: 42199, 2017. 
41 Mori M, Genda T, Ichida T, Murata A, Kamei M, Tsuzura H, Sato S, Narita Y, Kanemitsu Y, Ishikawa S, Kikuchi T, Shimada Y, Hirano K, Iijima K, Sugimoto K, Wada R, Nagahara A and Watanabe S: Aldo-keto reductase family 1 member b10 is associated with hepatitis b virus-related hepatocellular carcinoma risk. Hepatol Res 47(3): E85-E93, 2017.

42 Miura N and Koizumi S: Heavy metal responses of the human metallothionein isoform genes. Yakugaku Zasshi 127(4): 665673, 2007.

43 Dovrat S, Caspi M, Zilberberg A, Lahav L, Firsow A, Gur H and Rosin-Arbesfeld R: 14-3-3 and beta-catenin are secreted on extracellular vesicles to activate the oncogenic wnt pathway. Mol Oncol 8(5): 894-911, 2014.

44 Luo DX, Huang MC, Ma J, Gao Z, Liao DF and Cao D: Aldoketo reductase family 1 , member b10 is secreted through a lysosome-mediated non-classical pathway. Biochem J 438(1): $71-80,2011$
45 Huang L, He R, Luo W, Zhu YS, Li J, Tan T, Zhang X, Hu Z and Luo D: Aldo-keto reductase family 1 member b10 inhibitors: Potential drugs for cancer treatment. Recent Pat Anticancer Drug Discov 11(2): 184-196, 2016.

46 Grider A, Bailey LB and Cousins RJ: Erythrocyte metallothionein as an index of zinc status in humans. Proc Natl Acad Sci USA 87(4): 1259-1262, 1990.
Received October 19, 2018

Revised October 30, 2018

Accepted October 31, 2018 